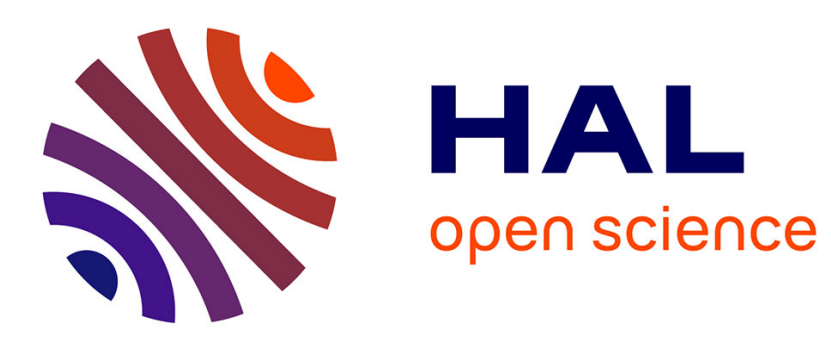

\title{
NEAR THRESHOLD FATIGUE CRACK GROWTH IN A 8090 LITHIUM CONTAINING Al ALLOY
}

\author{
R. Tintillier, H. Yang, Narayanaswami Ranganathan, J. Petit
}

\section{To cite this version:}

R. Tintillier, H. Yang, Narayanaswami Ranganathan, J. Petit. NEAR THRESHOLD FATIGUE CRACK GROWTH IN A 8090 LITHIUM CONTAINING Al ALLOY. Journal de Physique Colloques, 1987, 48 (C3), pp.C3-777-C3-784. 10.1051/jphyscol:1987391 . jpa-00226623

\section{HAL Id: jpa-00226623 https://hal.science/jpa-00226623}

Submitted on 1 Jan 1987

HAL is a multi-disciplinary open access archive for the deposit and dissemination of scientific research documents, whether they are published or not. The documents may come from teaching and research institutions in France or abroad, or from public or private research centers.
L'archive ouverte pluridisciplinaire HAL, est destinée au dépôt et à la diffusion de documents scientifiques de niveau recherche, publiés ou non, émanant des établissements d'enseignement et de recherche français ou étrangers, des laboratoires publics ou privés. 
NEAR THRESHOLD FATIGUE CRACK GROWTH IN A 8090 LITHIUM CONTAINING A1 ALLOY

\author{
R. TINTILLIER, H.S. YANG, N. RANGANATHAN and J. PETIT \\ Laboratoire de Mécanique et de Physique des Matériaux, \\ CNRS-UA 863, ENSMA, Rue Guillaume VII, \\ F-86034 Poitiers Cedex, France
}

\title{
ABSTRACT
}

Near threshold fatigue crack growth behaviour of a $2.2 \% \mathrm{Li}, 1.1 \% \mathrm{Cu}$ and $0.7 \% \mathrm{Mg}$ $8090 \mathrm{Al}$ alloy has been studied in air and vacuum at load ratios ranging from 0.01 to 0.8 , using compact tension specimens machined in TL and LT orientations in three aging conditions : $2 \mathrm{~h} 30$ at $160^{\circ} \mathrm{C}, 12 \mathrm{~h}$ at $190^{\circ} \mathrm{C}$ (T651) and $78 \mathrm{~h}$ at $210{ }^{\circ} \mathrm{C}$.

Comparison of the behaviour of the 8090 alloys with classical alloys 2024 T35 and 7075 T651 shows that lithium addition consists in a significant improvement of the near threshold crack growth resistance which has been analysed as a consequence of the planar slip mechanism observed in $\delta^{\prime}$ hardened matrix which results in substantial roughness-induced closure effects.

The influence of load ratio and texture are shown to be mainily related to crack closure and the propagation behaviour to be rationalized in terms of the effective stress intensity factor range $\Delta K_{\text {ff }}$ for given environmental and aging conditions. The influence of environment is discussed in terms of water vapour embrittlement from metallurgical studies.

\section{INTRODUCTION}

During the past few years there has been a renewed interest in understanding the mechanical properties and microstructural characteristics of aluminium alloys containing additions of Lithium because of the perspective of both substantial density reduction and elastic modulus increase. These new alloys involve no basic change in manufacturing methods, designs or technical maintenance for the end users. However, significant changes in microstructural features have been brought out from recent research and development of these materials. Specifically, complex structural hardening mechanisms have been studied and discussed since $1980 / 1-3 /$.

The lately late developped AT-Cu-Li-Mg alloys show large improvements in strength /ductility relationships as compared to first generation Lithium containing Al alloys $/ 4 /$ and mass savings about $10 \%$ might justify their use in aerospace applications.

Although there have been numerous reports on the relationship between composition, microstructure and microscopic properties of $L i$ containing Al alloys, few studies on their cyclic properties and specifically, on fatigue crack growth resistance, have been conducted. The purpose of this paper is to describe the main results of a detailed study on the fatigue crack propagation near threshold conditions in a new 8090 alloy which is compared to classical alloys type 2024 or 7075 .

\section{EXPERIMENTAL PROCEDURE}

The chemical composition of the 8090 alloys used for the present investigations is shown in Table I. Zirconium was added as the dispersoïd forming element $\mathrm{Al}_{3} \mathrm{Zr}$ which is effective to prevent recrystalisation $/ 5 /$ without adverse effect on fracture 
toughness. The unrecrystallised structure of this alloy leads to high stress levels due to $\mathrm{Cu}$ and $\mathrm{Mg}$ solid solutions strengthening (specifically for underaged conditions) in addition to $\left.\delta^{\prime}(A) L i\right)$ precipitation, and coprecipitation of $S^{\prime}(A)$ $\mathrm{Cu} \mathrm{Mg}$ ) needles (nearby peak aged conditions). This effect of $\delta$ ' precipitation is strongly enhanced by cold working. Overaged conditions are characterized by the development of PFZ, $\delta$ ' coarsening and precipitation at the grain boundaries.

Typical mechanical properties of the 8090 alloy in three tempered conditions are reported in Table IV for the extruded plates used in this study.

Tests were carried out on compact tension specimens machined in TL ou LT orientation from plates homogenized for $14 \mathrm{~h} 30$ at $535^{\circ} \mathrm{C}$, water quenched and stretched by $3.5 \%$ before tempering.

An environmenta 4 chamber mounted on an electrohydraulic machine was used in which a vacuum of $5.10^{-4} \mathrm{~Pa}$ could be obtained. In the laboratory air, the relative humidity was typicaliy $50 \%$.

The loading frequency was $35 \mathrm{~Hz}$. Load ratios from 0.01 up 0.8 were used. The crack was optically monitored and closure measurements were performed using a compliance method.

\section{EXPERIMENTAL RESULTS AND DISCUSSION}

Figure 1 shows that the fatigue crack growth resistance in the low and medium rate ranges of the $8090 \mathrm{~T} 651$ alloys tested in ambient air at a load ratio of 0.1 is better than the one of conventional alloys type 7075 T651 and 2024 T351 tested in the same conditions.

This result is consistent with previous observations indicating a substantial improvement in fatigue crack growth resistance of Al alloys with addition of Lithium higher than $2 \%$ in weight.

To get more detailed information about this attractive characteristic of the 8090 alloy; a study of several influencing parameters and factors have been undertaken. This paper presents the first results yet obtained.

- Influence of the load ratio on the crack growth behaviour of the 8090 T65I alloy tested in ambiant air.

Tests were conducted on $8090 \mathrm{~T} 65 \mathrm{~T}$ specimens machined in the LT orientation at load ratio $R$. ranging from 0.01 to 0.8 and in the $T L$ orientation at 0.1 and 0.5 . The corresponding da/dN vs $\Delta K$ bi-logarithmic plots are presented in Figures $2 a$ and $2 b$ respectively.

As classically observed on several metallic alloys including $A 1$ alloys, the crack growth resistance of the $8090 \mathrm{~T} 651$ decreases with increasing $R$, markedly at low crack propagation rates, and the threshold level decreases from $5.8 \mathrm{MPa} / \mathrm{mil}$ at $R=$ 0.01 to $1.5 \mathrm{MParm}$ at $\mathrm{R}=0.8$.

Figure 3 shows that this $R$ ratio effect is, to a great extent, rationalized in terms of the effective stress intensity factor $\Delta K_{\text {eff }}$ which accounts for the micromecha-
nical closure effects.

In all cases of $R$ ratio and orientation, highiy crystallographic crack paths associated with crack branching and facetted crack surfaces have been observed. Figure 5 features an example of the crystallographic aspect of the fracture surfaces near threshold at $R=0.1$. The presence of debris at low $R$ ratio suggests an abrasion process by surface rubbing. These observations are consistent with a $R$ ratio effect mainly controlled by the roughness induced closure mechanism as described by Suresh et a1. $/ 6 /$. 
In figure 3 , the apparent scatter observed in the mid rate range $\left(>10^{-5} \mathrm{~mm} /\right.$ cycle $)$ could be attributed to an interaction between the effects of closure and of environnement on the assumption that the influencing environmental phenomenon could be water vapour adsorption as suggested elsewhere for other Al alloys $/ 7 /$. In such conditions a slight increase in crack growth rate with increasing $R$ ratio would be consistent with increasing facility for water vapour transport up to the crack tip with increasing $R$ ratio $/ 8 /$. But the scatter observed near threshold must be first attributed to the large scatter inherent to closure measurements in a very low $\Delta K$ range. ( $\left.\Delta \mathrm{K}_{\mathrm{ff}}\right)_{\text {th }}$ could be related to some oxidation induced by surface rubbing or fretting as observed previously on alloys type $7075 / 9,10 \%$, especially at low $R$ ratio. Such formation of oxide deposits which can increase the $\Delta K$ threshold range by oxide-induced closure, can also act as water trap and induce an increase of the effective threshold range $/ 11 /$. The first results obtained from $x$ analysis of fracture surfaces in a scanning microscope are presented in Figure 4 . They show evidence of the presence near threshold of oxide deposits on the crack surface of a specimen tested in air at $R=0.5$ compared to a specimen tested in vacuum in the same other conditions (see below).

On the basis of the same reference work /11/ the transition plateau, with a slope close to 2, which is observed in figure 3 on all the curves, could be associated to the occurence of an hydrogen assisted crack growth mechanism, hydrogen being provided by the dissociation of molecules of water vapour adsorbed at the crack tip 112\%. Such a mechanism leads to a very low effective threshold range, about $0.9 \pm$ $0.4 \mathrm{MPa} \sqrt{\mathrm{m}}$.

\section{- Influence of the load ratio on the crack growth behaviour of the 8090 T651} alloy tested in vacuum.

Tests in vacuum were performed in the LT and TL orientations and at $\mathrm{R}$ ratio of 0.1 and 0.5 .

The $\mathrm{da} / \mathrm{dN}$ vs $\Delta K$ curves presented in Figure 6 suggest the folloving remarks.

- the threshold $\Delta K$ range decreases $20 \%$ with increasing $R$ ratio,

- there is no influence of the specimen orientation on crack propagation at $R=0.5$ except for a slight difference at $R=0.1$ in the mid rate range;

- the crack growth resistance in vacuum is comparable to the one in air at low $R$ ratio but is very much higher at high $\mathrm{R}$ ratio.

The $\mathrm{da} / \mathrm{dN}$ vs $\Delta \mathrm{K}$ ff curves plotted from closure measurements, which are presented in Figure 6 show that in vacuum the $R$ ratio and orientation effects are nicely taken into account with the effective stress intensity factor range. Consequently, these effects are only dependant upon the micromechanism governing crack closure. The first microfrac-tographic observations performed on the specimens tested in vacuum confirm the presence of a predominantly transgranular surface morphology as observed in air. The microstructure of the 8090 T651 alloy, envolving a dense, fine, coherent and shearable precipitation, enhances planar slip /13/, and near threshold conditions i.e. at low plastic deformation, the movement of dislocations at the crack tip can be localized into a single slip system in each grain $/ 13 \%$. Such a mechanism is consistent with the observed aspect of the fracture surfaces. The very much faster growth rates in an active environment observed at high $R$ ratio would suggest a strong decrease in the resistance of this al ioy when it is subjected to an alternative planar slip mechanism in the presence of water vapour.

The effective threshold range in vacuum was measured between 1.8 and 2.8. $\mathrm{MPa} \sqrt{\mathrm{m}}$. This range might be the intrinsic threshold range of the alloy. It is very close from the intrinsic threshold determined on several other Al alloys /11, 14/ which would suggest that it is essentially dependant on the matrix. In ambient air the effective threshold range is very much lower, about $0.9+0.4 \mathrm{MPa} \sqrt{\mathrm{m}}$, which appears to be characteristic of a Aluminium alloy/ambient air couple $/ 14 /$. 


\section{- Influence of tempering}

In order to characterize the influence of tempering on the fatigue crack growth resistance of the 8090 alloy, tests have been brought out on specimens in underaged (A) and overaged (C) conditions and compared to the tests performed on the peak aged (B) T651 alloy. The results obtained in air and in vacuum have been plotted in figure $7 \mathrm{a}$ and $7 \mathrm{~b}$ respectively.

In air the fatigue crack growth resistance of the 8090 alloys is shown to be lowered by aging while in vacuum no change is observed. Consequently, the decreasing resistance with aging time and/or temperature in air appears to be related to an increasing sensibility to water vapour with aging. The main changes in microstructure between $A$ and $C$ alloys consist in some coarsening of $\delta^{\prime}$ in the matrix and mainly precipitation of $\delta$ phase along grain boundaries associated to the development of PFZ. As shown recently on an overaged Al-Mg-Zn bicrystalline alloy $/ 15 /$, an embrittling effect could be induced by water vapour through the grain boundaries subjected to cyclic deformation. A similar mechanism could be invlolved in the case of alloy $\mathrm{C}$.

\section{CONCLUSIONS}

The higher fatigue crack growth resistance compared to classical alloys of the 8090 T65 I alloy, as observed on a reference test performed at a load ratio of 0.1 in ambient air, is mainly related to a large closure effect induced by the chaotic crack geometry due to the highly crystallographic fracture surfaces promoted by precipitation.

Moreover, such a crack geometry can reduce water vapour access at the crack tip, and, consequentiy, can limit the embrittling effect of this active gazeous phase.

In addition, a process of water vapour trappping by oxyde deposits build up on frac-ture surfaces near threshold could accentuate this limitation. Compared to vacuum, tests performed in air at high $R$ ratio have shown a decrease of the influence of geometry and oxidation of the crack surfaces while the effect of water vapour embrittlement becomes predominant, leading to very low threshold level and near-threshold growth resistance.

The lower resistance of the overaged alloy is also shown to be related to an embrittling effect of water vapour which could be located at the grain boundaries.

\section{REFERENCES}

1 - T.H. Sanders J.R. and E.A. Starke, Jr, "Aluminium-Lithium Alloys, eds TH Sanders, Jr and E.A. Starkes, Jr., Pub. TMS-AIME, Warrendale, P.A. (1981).

2 - T.H. Sanderz, Jr. and E.A. Starke, Jr., Aluminium-Lithium Alioys II, eds T.H. Sanders Jr and E.A. Starke, Jr., Pub. TMS-AIME, Warrendale, P.A. 51983).

3 - P. Saimfort, B. Dubost, P. Meyer, "Symposium of Ligth Metals" "Advance in Materials R \& D for Transport", European Material Research Society Fall Meeting, Strasbourg, France, Nov.26-28, 1985.

4 - E.A. Starke, Jr, T.H. Sanders, Jr and I.G. Palmer, J.of Metals, vol. 33, $n^{\circ} 8$, 1981, pp.24-33.

5 - S. Rystad and N. Ryum, Aluminum 53 (1977) p. 193-195.

6 - S. Suresh and R.0. Ritchie, "Near threshold fatigue crack propagation : a perspective on the role of crack closure", Fatigue Crack Growth Threshold Concepts, eds. D. Davidson and S. Suresh, TMS-AIME? pp.227-261.

7 - J. Petit, Proc. Int. Symp. TMS/AIME/ASME Philadelphia U.S.A. (1983) p.3.

8 - B. Tomkins : Inst. of Mech. Engineers, London, 111 (1977).

9 - S. Suresh, G.F. Zamiski and R.0. Ritchie, Met. Trans. 12A, (1981), 1435-1443.

10- P. Renaud, P. Violan, J. Petit and D. Ferton, Scripta Met. 16, (1982), 1371 1316.

11- J. Petit and A. Zeghloul, Proc. ISFT "Fatigue Threshold", Stockholm, J. BäcKiund, A. BTom and C.J. Beevers eds, EMAS, Warley (U.K.)

12- R.P. Wei, ASTM-STP 675 (1979) p. 816.

13- E. Hornbogen and K.H. Zum Gahr, Metailograhy 8 (1975), p. 181. 
14- J. Petit and A. Zeghloul, The Behaviour of Short Fatigue Cracks, EGF Pub. 1 (Ed. by K.J. Miller and E.R de los Rios) 1986, Mech. Eng. Pub. London, pp.163-177.

15- A. Niegel, H.J. Gudladt and V. Gerold, Proc. Fatigue 87, Charlottesvilie, Va USA, June 28 - July, 1987.

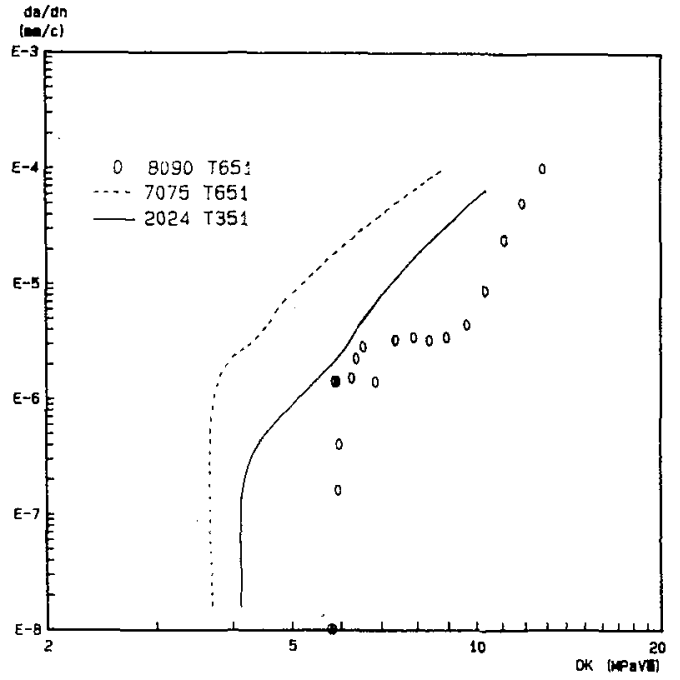

Fig. 1- Comparison of crack growth data obtained in air at a load ratio $R=0.1$ between a) $10 y$ y $8090 \mathrm{~T} 651$ and conventionnal alloys $7075 T 651$ and $2024 T 351$.

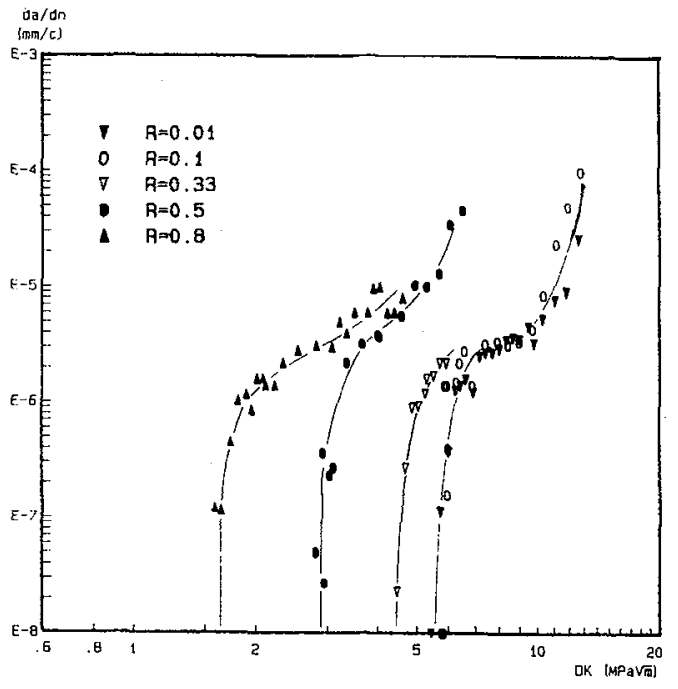

(a)

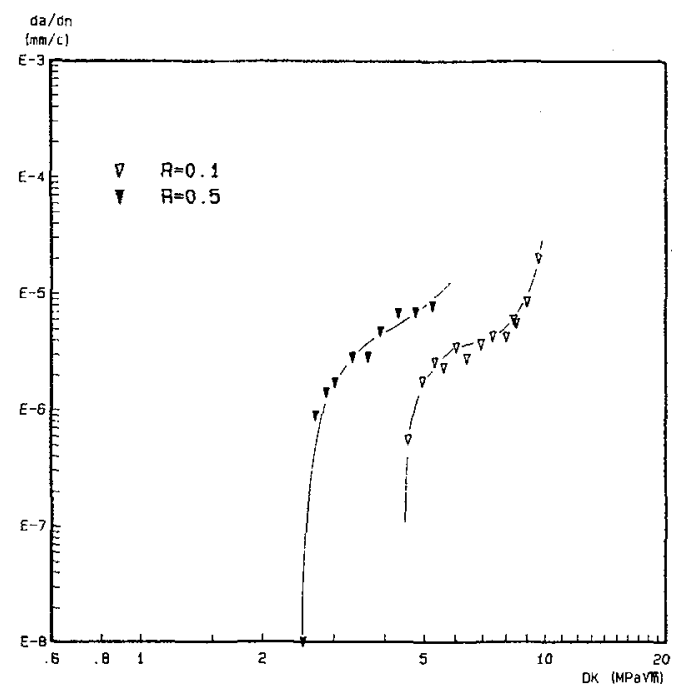

(b)

Fig2 - Crack growth rates in air in alloy 8090 T65]
a) in LT orientation
b) in TL orientation 


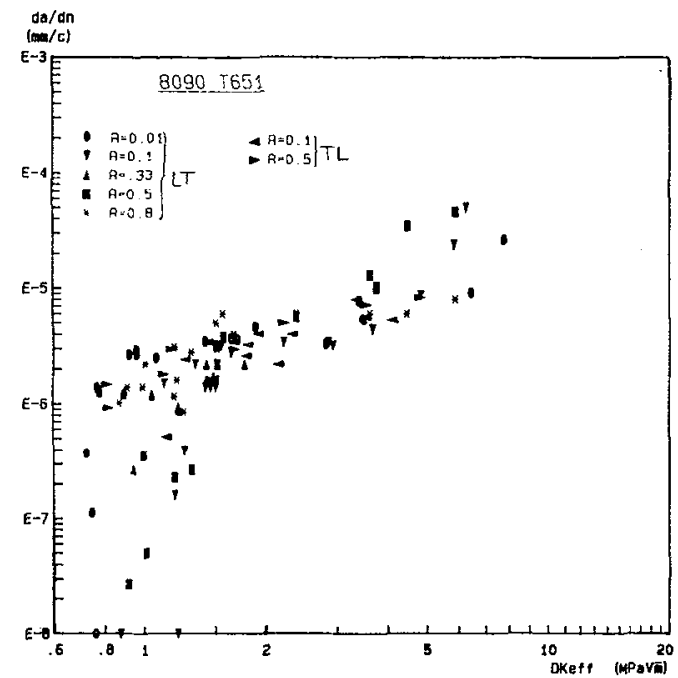

Fig.3 - da/dN vs Keff plots for alloy 8090 T651 tested in air at different load ratios and in $L T$ and $T L$ orientations.

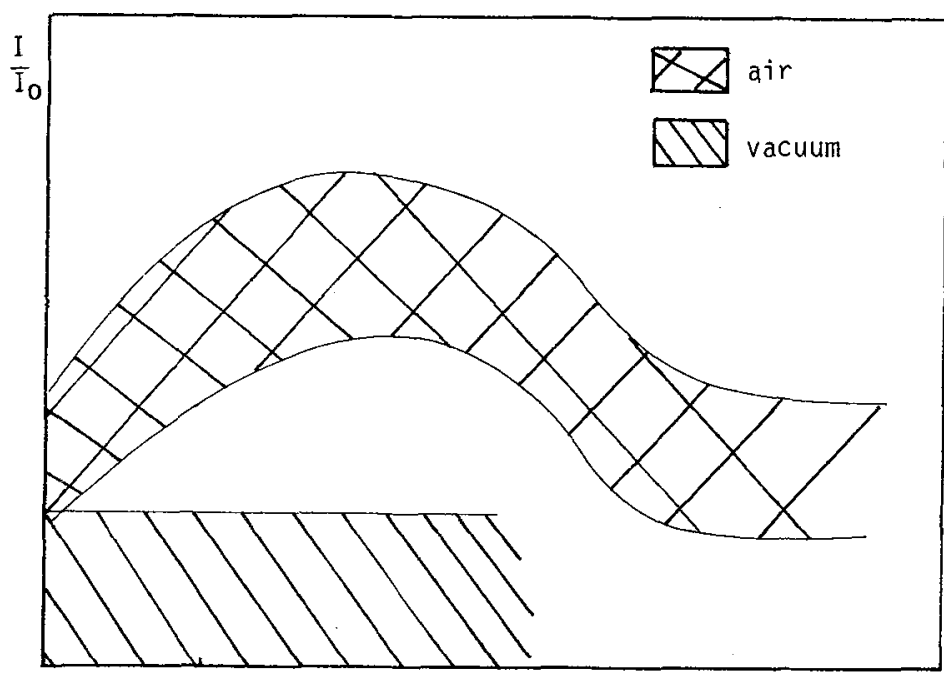

threshold 1 (ini

length from threshold position

Fig. 4 - Oxide thickness measurements performed on alloy 8090 T651 tested at $R=0.5$ in air and in vacuum. 

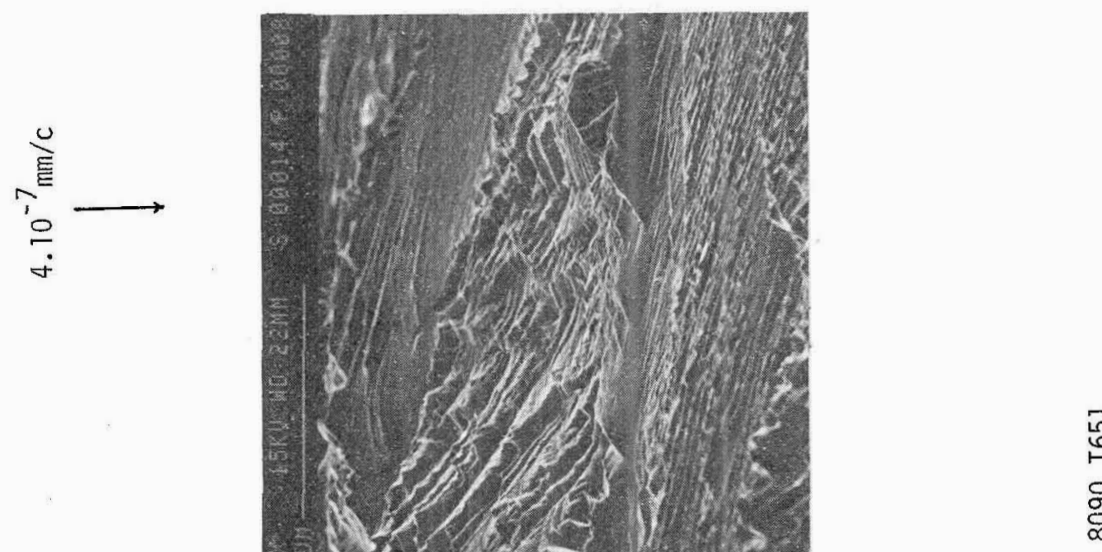

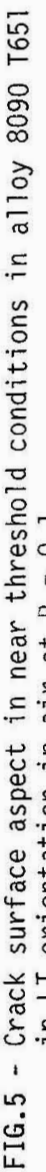

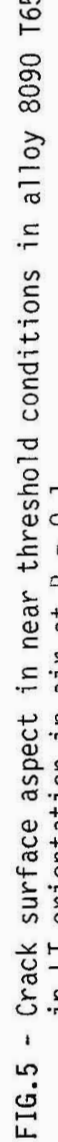

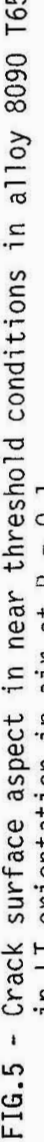

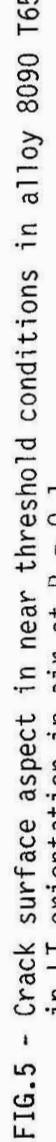

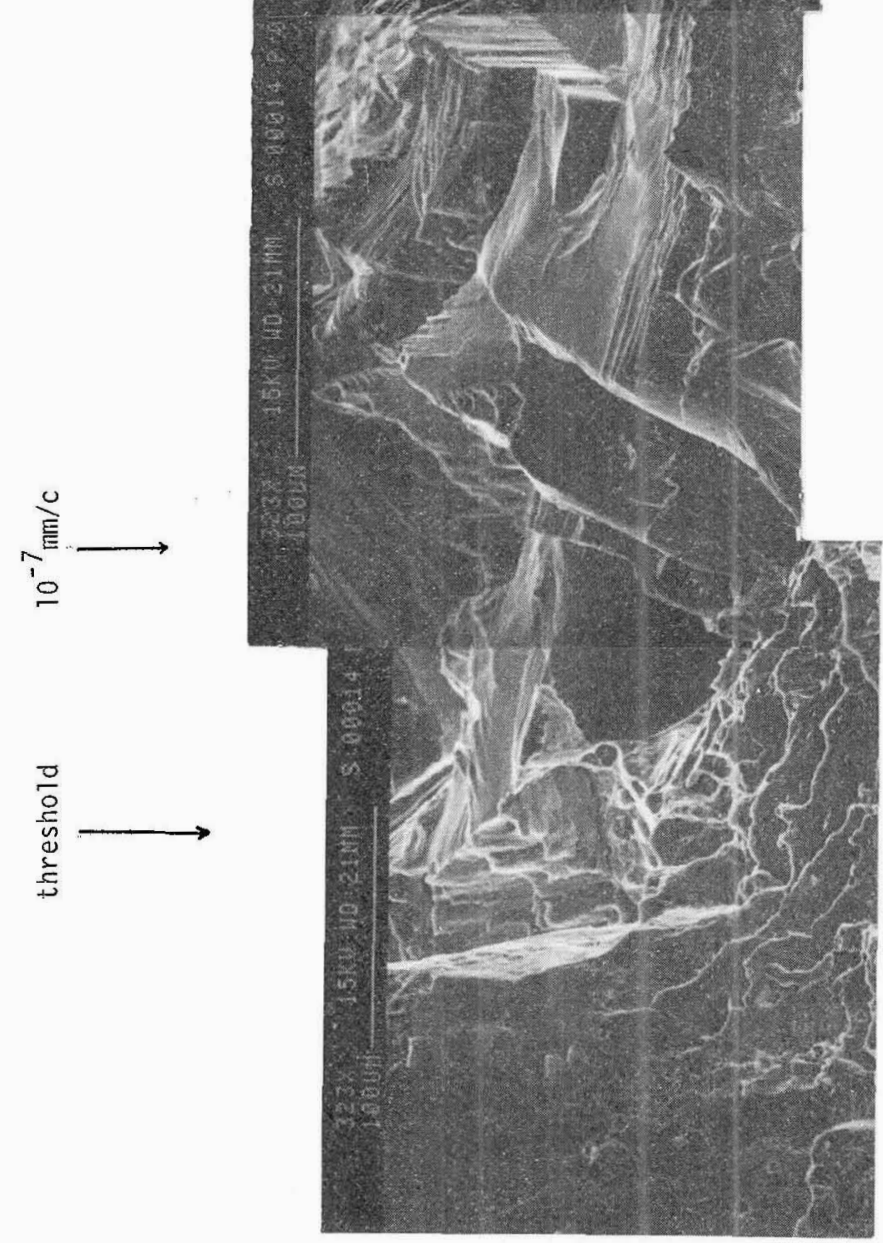




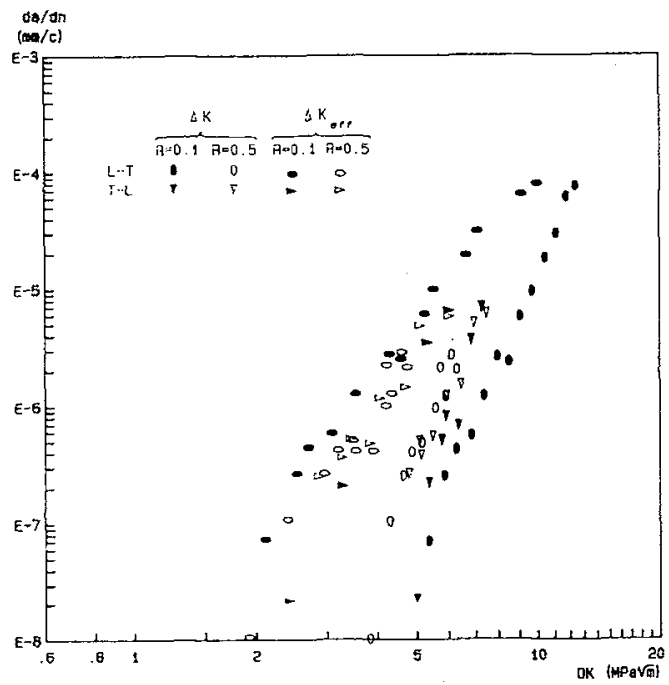

Fig.6 - $\Delta K$ vs da/dN and $\Delta K$ eff plots for alloy $8090 T 651$ tested in vacuum in TL and LT orientation at $R=0.1$ and $R=0.5$.

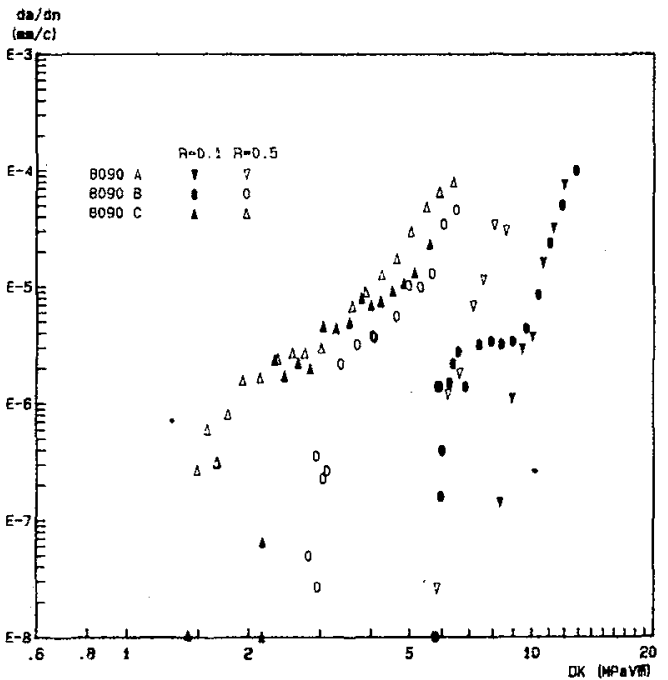

(a)

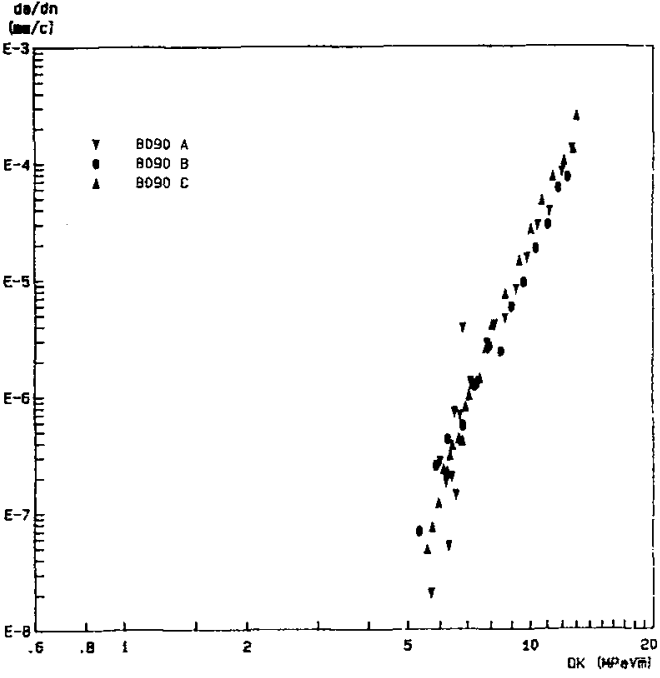

(b)

Fig:7 - Crack growth data for alloy 8090 in three tempering conditions A (underaged), B (T651) and C (overaged)
a) in air
b) in vacuum. 